\title{
ELABORAÇÃO DE BANCO DE DADOS GEOGRÁFICOS PARA PLANEJAMENTO E GESTÃO DE UNIDADES DE CONSERVAÇÃO
}

\author{
Otacílio Lopes de Souza da Paz ${ }^{(\mathrm{a})}$, Josemar Pereira da Silva ${ }^{(\mathrm{b})}$, Eduardo Vedor de Paula $^{(\mathrm{c})}$
}

(a) Departamento de Geografia/Universidade Federal do Paraná, otacilio.paz@ gmail.com

(b)Departamento de Geografia/Universidade Federal do Paraná, josemarps@ gmail.com

(c) Departamento de Geografia/Universidade Federal do Paraná, edugeo@ufpr.br

\section{Eixo: GEOTECNOLOGIAS E MODELAGEM ESPACIAL EM GEOGRAFIA FÍSICA}

\begin{abstract}
Resumo
Banco de dados geográficos (BDG) apresenta grande importância enquanto subsídio ao planejamento e à gestão ambiental. Discentes da graduação e pós-graduação em Geografia da Universidade Federal do Paraná desenvolvem desde 2014 uma metodologia para elaboração de BDG, a partir de experiências na produção do diagnóstico ambiental da Área de Proteção Ambiental de Guaraqueçaba e de outras unidades de conservação (UCs) no litoral norte do Paraná. Objetiva-se apresentar a metodologia em desenvolvimento, elencando resultados na aplicação entre os anos de 2015 e 2016. Os procedimentos metodológicos dividem-se em 4 etapas: avaliação, sistematização organizacional,qualidade e elaboração de produtos cartográficos. Foram organizados 181 dados geoespaciais em 35 categorias temáticas. Ganha destaque a metodologia por aplicar critérios de controle de qualidade, permitindo a interoperabilidade dos dados. Espera-se que a metodologia apresentada continue seu desenvolvimento aliando a teoria da academia com a prática profissional e que seja aplicada em outras UCs.
\end{abstract}

Palavras chave: Geotecnologias, Dados Geoespaciais, Qualidade da Informação, Áreas Protegidas.

\section{Introdução}

Os Bancos de Dados Geográficos (BDG) associados aos Sistemas de Informações Geográficas (SIG) consistem em ferramentas eficientes capazes de armazenar, gerir e distribuiruma grande quantidade de informações geoespaciais que podem subsidiar estudos ambientais e o processo de tomada de decisão (COUTINHO, 2010).

No entanto, é necessário o desenvolvimento de metodologias para estruturação e gestão de BDG em diversas finalidades, como por exemplo, para o planejamento e gestão ambiental. Ainda, é necessário clareza nas metodologias propostas, onde sejam destacadas as formas de sistematização do volume de dados e regras para controle de qualidade (ISO, 2003a; COUTINHO, 2010).

Neste contexto, uma metodologia para construção de BDG é desenvolvida desde 2014 por alunos da graduação e pós-graduação em Geografia da Universidade Federal do Paraná (UFPR). Estas atividades 


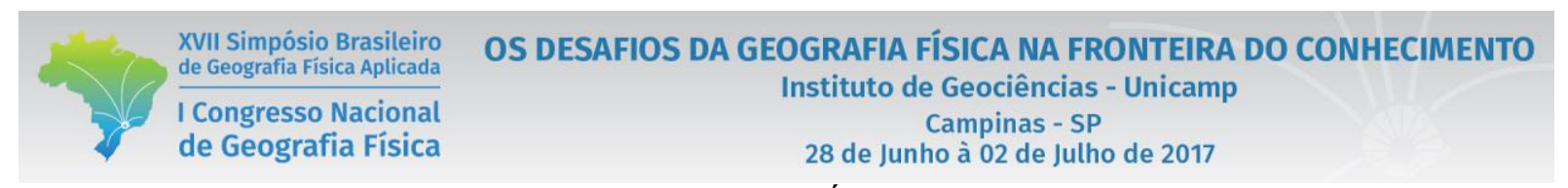

fazem parte da elaboração do diagnóstico ambiental da Área de Proteção Ambiental de Guaraqueçaba e de outras Unidades de Conservação (UCs) no litoral norte do Paraná.

Este diagnóstico ambiental é produzido na disciplina "Práticas em Planejamento e Gestão Ambiental GB130”, ofertada em caráter optativo pelo departamento de Geografia da UFPR, fazendo parte do Termo de Cooperação Técnica n²3075.016923/2014-19, celebrado entre a UFPR o Instituto Chico Mendes de Conservação da Biodiversidade (ICMBio). O presente artigo tem por objetivo apresentar a metodologia em desenvolvimento para construção de BGD, bem como os resultados da sua aplicação nos anos de 2015 e 2016.

\section{Procedimentos metodológicos}

A área de abrangência do estudo no diagnóstico contempla as seguintes UCs federais: Área de Proteção Ambiental (APA) de Guaraqueçaba, Estação Ecológica (ESEC) de Guaraqueçaba, Reserva Biológica (REBIO) Bom Jesus e Parque Nacional (PARNA) de Superagui. Todas as UCs supracitadas estão localizadas no litoral norte do estado do Paraná (figura 1).

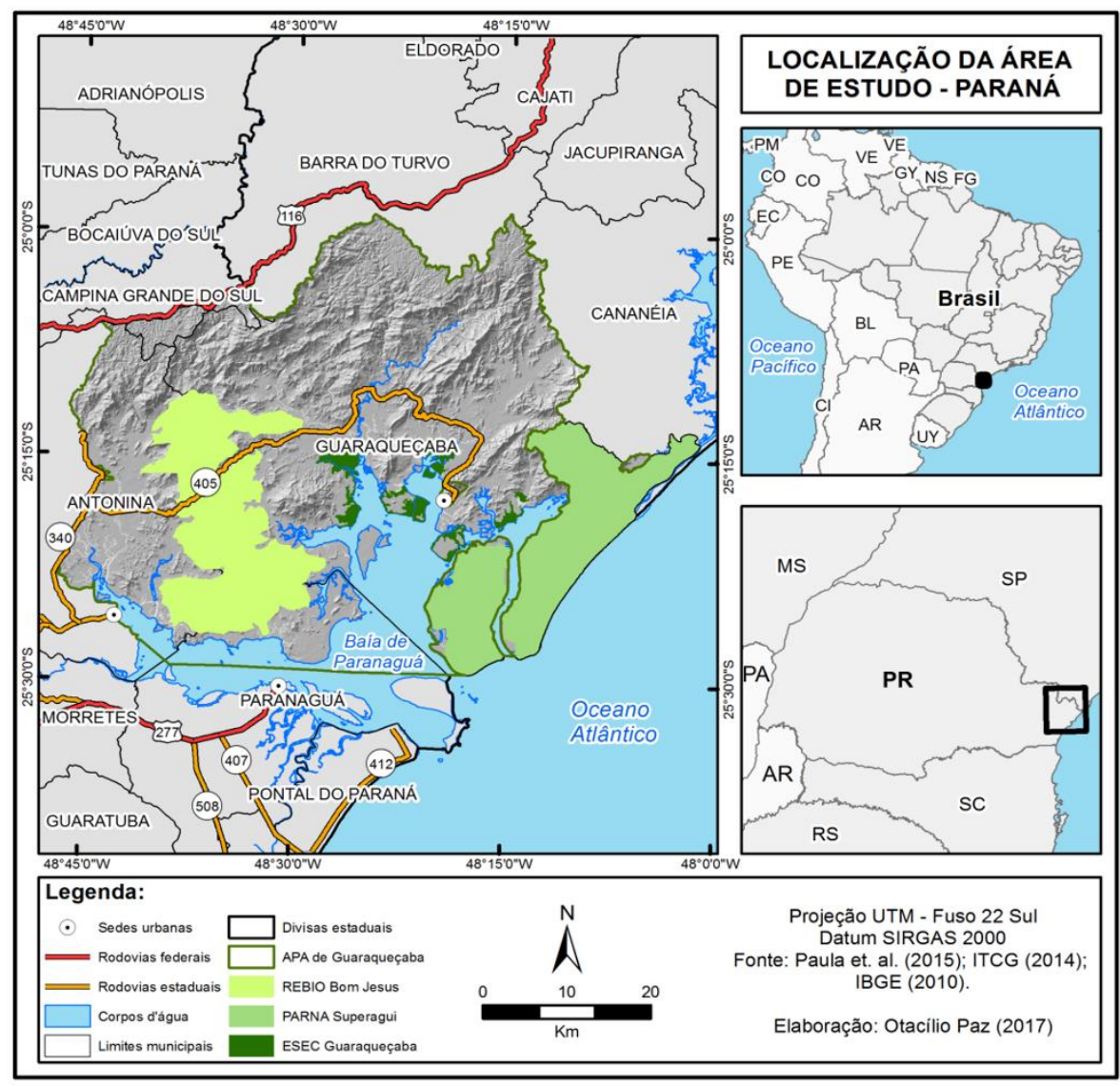

de estudo. Fonte: Os autores (2017).

Figura 1 - Localização da área 
XVII Simpósio Brasileiro de Geografia Fisica Aplicada

I Congresso Nacional de Geografia Física
OS DESAFIOS DA GEOGRAFIA FÍSICA NA FRONTEIRA DO CONHECIMENTO

Instituto de Geociências - Unicamp

Campinas - SP

28 de Junho à 02 de Julho de 2017

Entende-se como Banco de Dados Geográficos (BDG), uma base de dados geoespaciais (arquivos vetoriais, matriciais, tabelas, entre outros), sistematizada por categorias, com padronização estabelecida, com função de consulta e aplicação em softwares de SIG (COUTINHO, 2010).

As etapas metodológicas estão apresentadas na figura 2, sendo dividido em 4 momentos: Avaliação dos dados geoespaciais (Avaliação), Sistematização organizacional (Organização), Controle de qualidade (Qualidade) e elaboração de produtos cartográficos (Aplicação). É apresentado também a temporalidade de cada etapa, totalizando 6 meses.

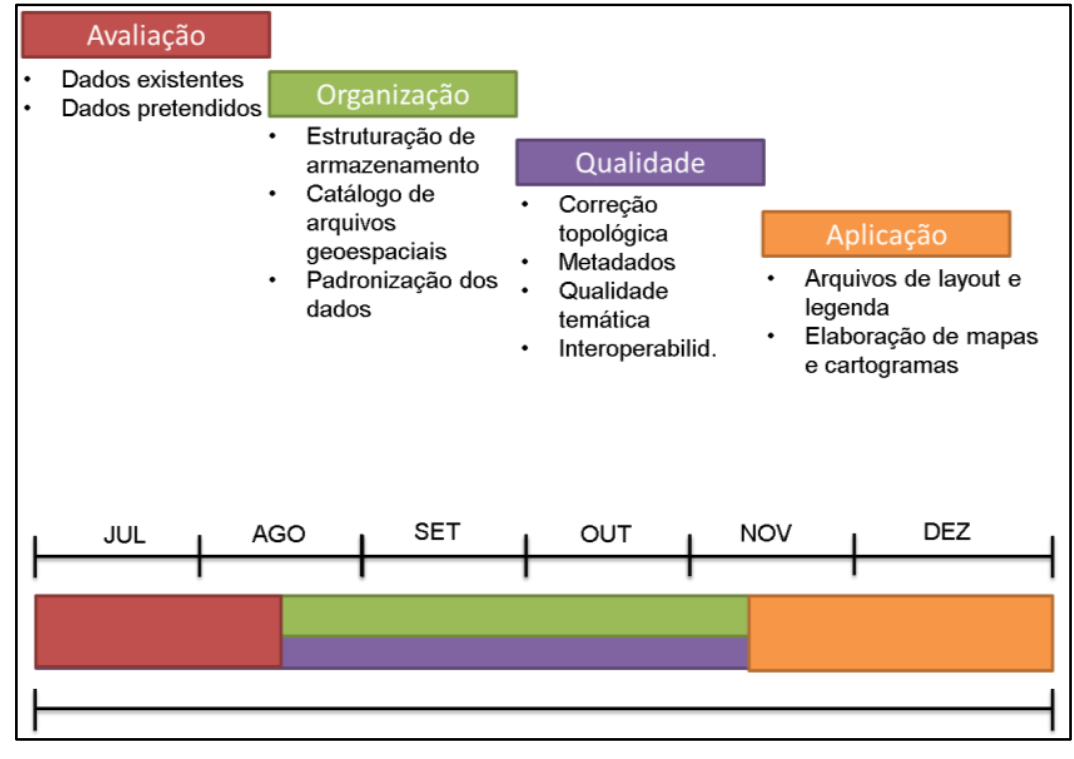

elaboração do BDG. Fonte: Os autores (2017).

O software padrão usado na criação, edição, padronização e armazenamento dos dados geoespaciais foi o ArcGIS 9.3.1, disponibilizado pelo Laboratório de Geoprocessamento (LABIGEO) do Setor de Ciências da Terra da UFPR.

A elaboração do BDG inicia-se com a necessidade de produtos cartográficos (mapas e cartogramas) que subsidiem o diagnóstico ambiental das UCs supracitadas. A primeira etapa é o levantamento de dados existentes e de dados a serem adquiridos junto àórgãospúblicos e ONGs, ou extraídos de estudos técnicos e/oucientíficos (dados secundários). No levantamento também deve constar os dados geoespaciais a serem produzidos pelos técnicos participantes do estudo ambiental (dados primários).

Foi necessária a revisão dos limites da APA de Guaraqueçaba e do PARNA de Superagui, em função da incompatibilidade dos dados existentes com a base cartográfica planialtimétrica disponível para a área (escala 1:25.000). Os limites foram revisados utilizando memoriais descritivos (quadro I) e folhas topográficas. 
XVII Simpósio Brasileiro de Geografia Fisica Aplicada

I Congresso Nacional de Geografia Física
OS DESAFIOS DA GEOGRAFIA FÍSICA NA FRONTEIRA DO CONHECIMENTO

Instituto de Geociências - Unicamp

Campinas - SP

28 de Junho à 02 de Julho de 2017

Quadro I - Memoriais descritivos usados para revisão dos limites da APA de Guaraqueça e PARNA de Superagui

\begin{tabular}{|c|c|}
\hline Memorial descritivo & Descrição \\
\hline $\begin{array}{c}\text { Decreto } \mathrm{n}^{\circ} 90.883, \text { de } 31 \text { de janeiro de } \\
1985\end{array}$ & $\begin{array}{c}\text { Criação da Área de Proteção Ambiental de } \\
\text { Guaraqueçaba }\end{array}$ \\
\hline $\begin{array}{c}\text { Decreto } \mathrm{n}^{\circ} 97.688, \text { de } 25 \text { de abril de } \\
1989\end{array}$ & Criação do Parque Nacional do Superagui \\
\hline $\begin{array}{c}\text { Decreto } \mathrm{n}^{\circ} 9.513, \text { de } 20 \text { de novembro de } \\
1997\end{array}$ & Amplia os limites do Parque Nacional do Superagui \\
\hline
\end{tabular}

Nos limites norte da APA de Guaraqueçaba, com o estado de São Paulo, foram utilizadas as folhas topográficas 1:50.000 (figura 3), o que se justifica devido àexistência de uma área de litígioentre São Paulo e Paraná (região de Serra Negra) (CAVELLANI, 2014). As folhas topográficas 1:25.000 consideram que a região de Serra Negra pertence ao Paraná, contrapondo os mapas do Instituto Brasileiro de Geográfia e Estatística (IBGE).Todavia, como a APA de Guaraqueçaba se caracteriza como uma UC federal optou-sepela divisão estadual do IBGE, presente nas folhas 1:50.000.

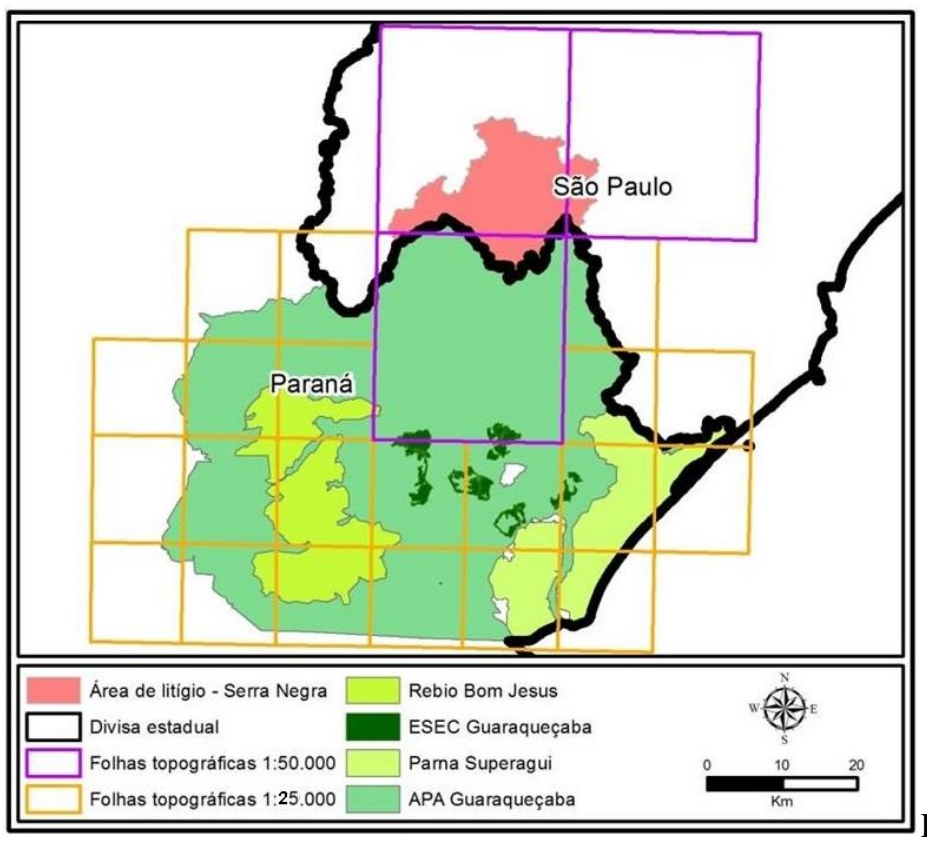

Figura 3 - Folhas topográficas usadas para revisão dos limites da APA de Guaqueçaba e PARNA do Superagui. Fonte: Os autores (2017).

Os limites da REBIO Bom Jesus não foram revisados pois essa UCjá estava delimitada com base nas folhas 1:25.000 (Decreto $\mathrm{s} / \mathrm{n}^{\mathrm{o}}$, de 5 de junho de 2012). Os limites da ESEC de Guaraqueçaba não foram revisados, pois o decreto de criação da ESEC descreve que os limites da mesma são as áreas de manguezais no interior de um retângulo envolvente, acrescida as ilhas da Banana e da Galheta (Decreto $\mathrm{n}^{\circ}$ 93.053 - 1986). 


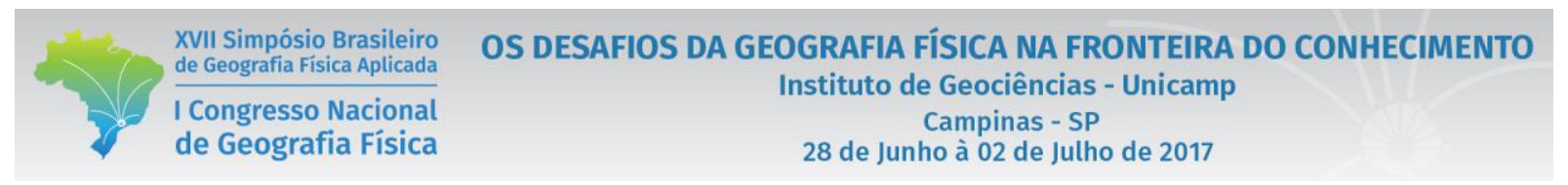

$\mathrm{Na}$ segunda etapa foi definida a sistematização dos arquivos, sendo padronizada a nomenclatura e a estrutura de pastas do BDG. A estrutura de pastas foi construída com base nas categorias temáticas apresentadas no Perfil de Metadados Geoespaciais do Brasil (Perfil MGB) (CONCAR, 2009), sendo inserido o código e o nome da categoria de informação (figura 4).

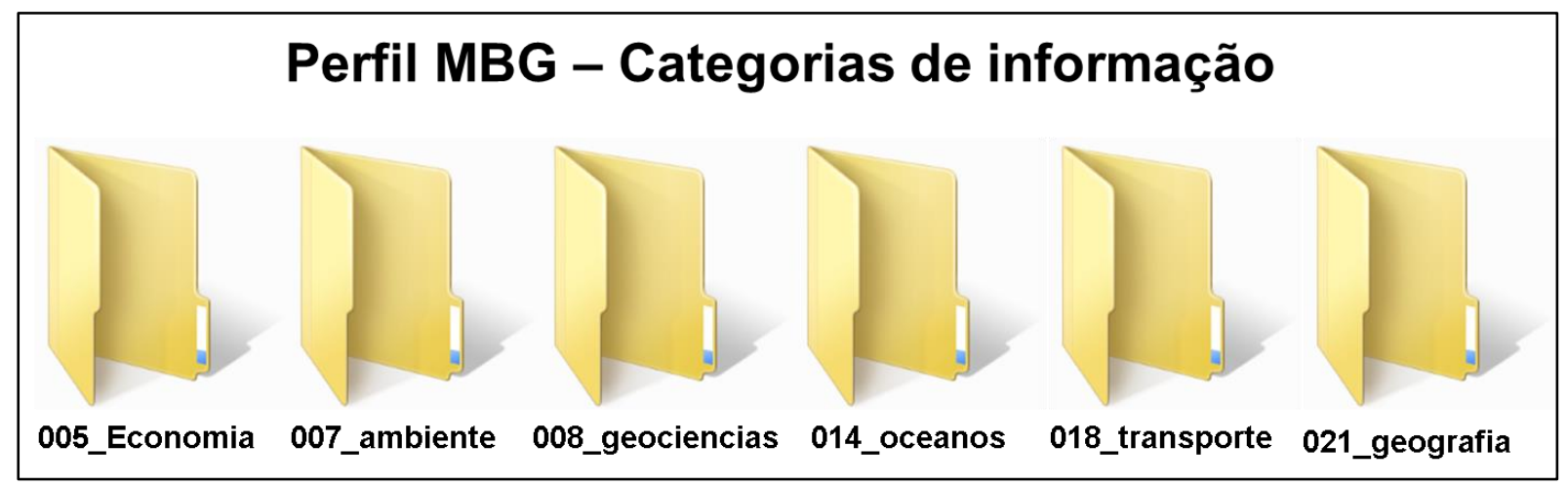

Figura 4 - Estrutura de pastas do BDG. Fonte: Os autores (2017).

A padronização da nomenclatura dos arquivos demandou a criação de uma codificação própria. A codificação de cada arquivo leva seis informações, a citar: ano do arquivo, código da categoria temática, código da subpasta do arquivo, estrutura do arquivo (vetorial, matricial, tabelas, entre outros), número do arquivo na pasta e nome do arquivo (definido em até 21 caracteres). A proposta ganha destaque por sistematizar a nomenclatura dos arquivos, facilitando sua interpretação e localização. Um exemplo da aplicação da proposta é ilustrado na figura 5.

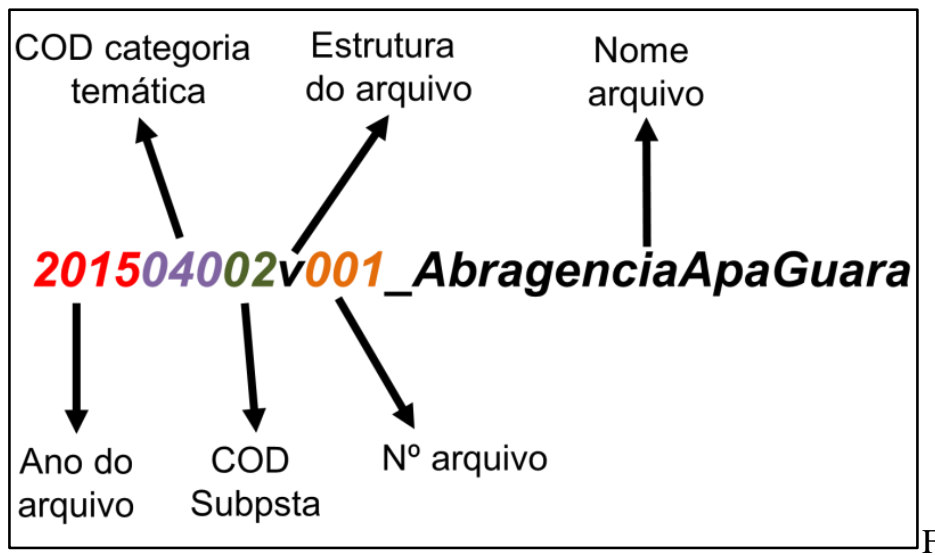

geoespaciais. Fonte: Os autores (2017).

Ainda na organização e padronização dos arquivos, foi necessária a definição da projeção cartográfica e do sistema geodésico de referência (datum). A projeção cartográfica UTM (Universal Transversa de Mercator) - fuso 22 Sul foi definida para maior parte dos arquivos, com exceção dos arquivos com 
dimensão nacional (ultrapassando o fuso), sendo nesses adotado a projeção lat/long (projeção cilíndrica simples).

A partir da publicação da resolução da presidência do IBGE No 1/2015 (IBGE, 2015), é adotado como oficial para o Brasil o Sistema de Referência Geocêntrico para as Américas (SIRGAS), em suarealização de 2000 (SIRGAS2000). No entanto, grande parte dos dados secundários foram elaborados em sistemas geodésicos de referência pretéritos, tais como o South Americam Datum de 1969 e 1996 (SAD69/96) e o Córrego Alegre 1961 ou Córrego Alegre 1970+1972.

A conversão errônea entredatumpode resultar em distorções ou deslocamentos que prejudicam análises espaciais e asrepresentações cartográficas (DALAZOANA; FREITAS, 2002). Assim, foram testados os métodos de conversão propostos pelo IBGE, pelo Instituto Nacional de Pesquisas Espaciais (INPE) e pelossoftwaresArcGIS e Qgis.

O controle de qualidade dos dados geoespaciais pautou-se nas recomendações técnicas e de trabalhos científicos listados no quadro II. Esses trabalhos descrevem procedimentos para o controle de qualidade de dados geoespaciais na cartográfia digital, elencando tópicos como a consistência topológica, metadados, acurácia posicional ou geométrica, entre outros.

Quadro II - Documentostécnicos e trabalhos científicos de referencia para o controle de qualidade de dados geoespaciais

\begin{tabular}{|c|c|c|}
\hline Nome & Descrição & Fonte \\
\hline ISO 19114 & $\begin{array}{c}\text { Determina critérios para avaliação da qualidade de } \\
\text { dados geoespaciais }\end{array}$ & (ISO, 2003a) \\
\hline ISO 19115 & Princípios de metadados geoespaciais & (ISO, 2003b) \\
\hline ISO 19157 & $\begin{array}{c}\text { Estabelece os princípios para descrever a qualidade } \\
\text { dos dados geoespaciais (atualização da ISO 19114) }\end{array}$ & (ISO, 2013) \\
\hline Perfil MGB & $\begin{array}{c}\text { Descreve procedimentos para preenchimento de } \\
\text { metadados de dados geoespaciais }\end{array}$ & (CONCAR, 2009) \\
\hline ET-ADGV & $\begin{array}{c}\text { Especificação Técnica para a Aquisição de Dados } \\
\text { Geoespaciais Vetoriais }\end{array}$ & (DSG, 2011) \\
\hline $\begin{array}{c}\text { Fundamentals of spatial } \\
\text { data quality }\end{array}$ & $\begin{array}{c}\text { Apresenta conceitos de qualidade de dados } \\
\text { geoespaciais, visando minimizar os riscos de } \\
\text { utilização indevida de dados na tomada de decisão. }\end{array}$ & $\begin{array}{c}\text { JEANSOULIN, 2006) } \\
\text { (DEVILLERS; }\end{array}$ \\
\hline
\end{tabular}

A verificação da consistência topológica consistiu na averiguação dos erros da estrutura lógica nos arquivos vetoriais de vazios entre os polígonos (gaps), sobreposição entre os polígonos (overlap), duplicadas de feições e geometrias inválidas (figura 6). 


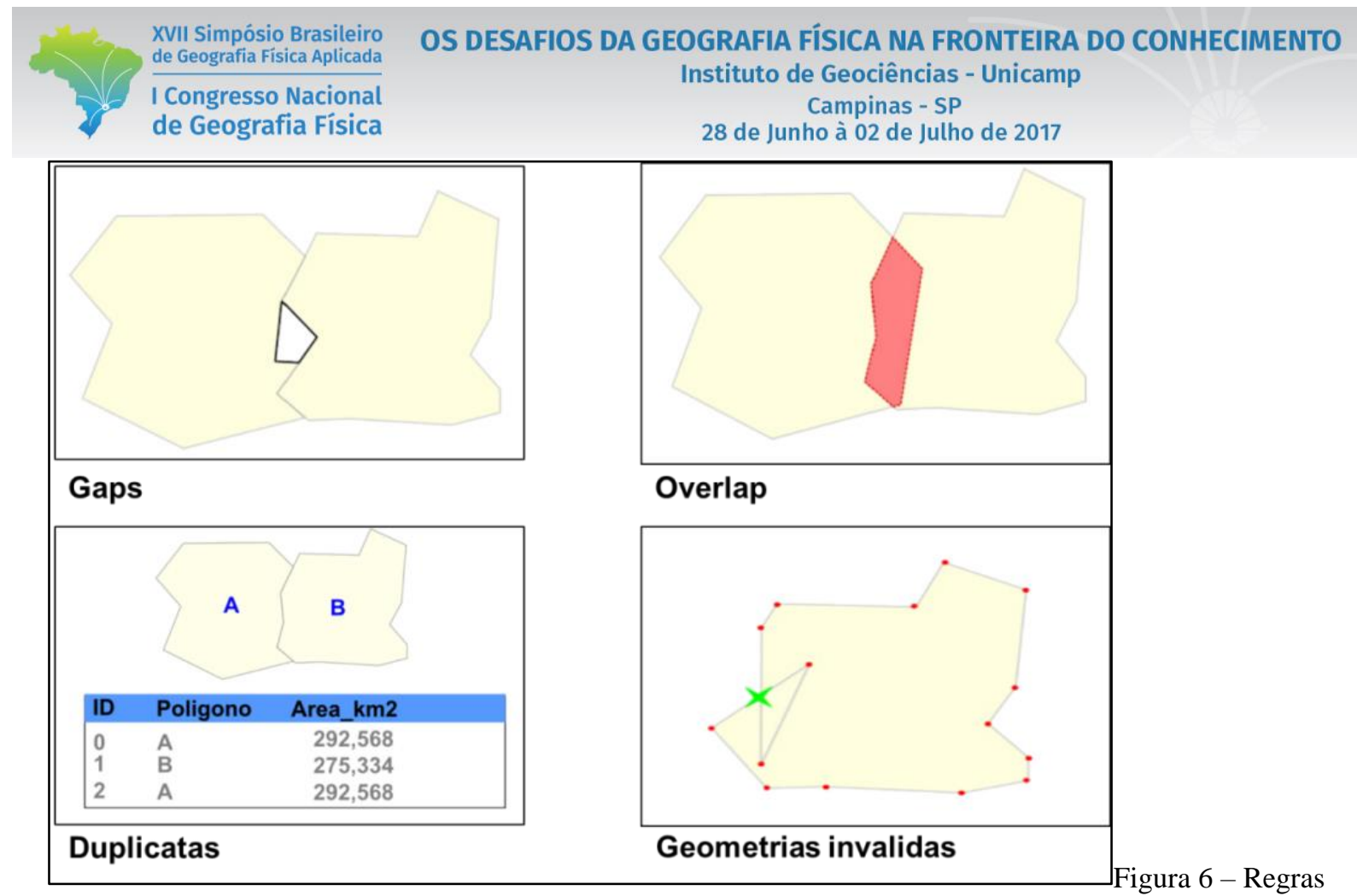

topológicas aplicadas. Fonte: (ESRI, 2010)

Os metadados foram preenchidos de acordo com a recomendação do Perfil MGB (CONCAR, 2009). Foi adotada a versão sumarizada do perfil de metadados (figura 7) em função do tempo disponível para a construção do BDG. Os metadados foram salvos no BDG em formato de tabela eletrônica (formato XLS).

\begin{tabular}{|c|c|c|c|}
\hline \multicolumn{4}{|c|}{ Entidades e elementos do Núcleo de Metadados do Perfil MGB Sumarizado } \\
\hline Entidade / Elemento & Obrigatoriedade & Entidade / Elemento & Obrigatoriedade \\
\hline 1. Título & obrigatório & $\begin{array}{l}\text { 12. Tipo de Representaçã̃o } \\
\text { Espacial }\end{array}$ & opcional \\
\hline 2. Data & obrigatórío & 13. Sistema de Referência & obrigatório \\
\hline 3. Responsável & obrigatório & 14.Linhagem & opcional \\
\hline 4. Extensão Geográfica & condicional & 15.Acesso Online & opcional \\
\hline 5. Idioma & obrigatório & 16.Identificador Metadados & opcional \\
\hline $\begin{array}{l}\text { 6. Código de Caracteres do } \\
\text { CDG }\end{array}$ & condicional & $\begin{array}{l}\text { 17. Nome Padråo de } \\
\text { Metadados }\end{array}$ & opcional \\
\hline 7. Categoria Temática & obrigatório & $\begin{array}{l}\text { 18. Versão da Norma de } \\
\text { Metadados }\end{array}$ & opcional \\
\hline 8. Resoluçã̃o Espacial & opcional & 19.Idioma dos Metadados & condicional \\
\hline 9. Resumo & obrigatório & $\begin{array}{l}\text { 20.Código de Caracteres dos } \\
\text { Metadados }\end{array}$ & condicional \\
\hline 10.Formato de Distribuiçã̃o & obrigatório & 21.Contato para Metadados & obrigatório \\
\hline $\begin{array}{l}\text { 11. Extensảo Temporal e } \\
\text { Altimétrica }\end{array}$ & opcional & 22.Data dos Metadados & obrigatório \\
\hline & & 23. Status & obrigatório \\
\hline
\end{tabular}

sumarizado. Fonte: (CONCAR, 2009)

Figura 7 - Perfil de metadados 
A elaboração dos produtos cartográficos (mapas e cartogramas) seguiu recomendações do IBGE (1998) e Timbó (2001). A legenda dos mapas e cartogramas foram salvas em formato LYR, sendo armazenada juntamente com os arquivos de layout (formato MXD) no BDG.

\section{Resultados e discussão}

O BDG gerado para subsidiaro diagnóstico ambiental está em sua $2^{\mathrm{a}}$ versão. A primeira versão, gerada em 2015, contava com 151 dados geoespaciais (tanto camadas matriciais quanto vetoriais). A versão de 2016 possui 181 dados geoespaciais em 35 categorias temáticas, sendo alocada no servidor interno da UFPR com tamanho aproximado de 20 gigabytes.

Durante a conversão de datum dos dados geoespaciais, os valores de deslocamento $\mathrm{X}$ e Y apresentaram variações significativas entre os métodos testados (quadro III). O método de conversão adotado (indicado em amarelo no quadro III) foi o apresentado pelo software ArcGIS 9.3.1, por ser compatível com as imagens do satélite rapideye (compatíveis com a escala 1:50.000 e com o datum SIRGAS 2000), disponibilizada pelo Ministério do Meio Ambiente (MMA) no portal GeoCatalogo.

Quadro III - Diferenças na transformação de datum nos métodos aplicados

\begin{tabular}{|c|c|c|}
\hline Conversão entre datum & Eixo X & Eixo Y \\
\hline ArcGIS 9.2 & 48,301 & 53,74 \\
\hline ArcGIS 9.3 & 47,593 & 52,844 \\
\hline ArcGIS 9.3.1 & 49,129 & 51,6 \\
\hline ArcGIS 10 & 10 & 12 \\
\hline ArcGIS 10.1 & 10 & 12 \\
\hline ArcGIS 10.2 & 10 & 12 \\
\hline ArcGIS 10.3 & 10 & 12 \\
\hline Qgis 2.8.1 & 17,45 & 22,43 \\
\hline Calculadora INPE & 55,6 & 68.52 \\
\hline ProGrid IBGE & 67,35 & 3,88 \\
\hline
\end{tabular}

Os limites disponibilizados para a área de abrangência do estudo obtidos junto ao ICMBio, World Wide Fund for Nature (WWF) e MMA apresentaram diferenças na área total das UCs (quadro IV) e na geometria dos polígonos.Essas divergências de área são justificadas pela escala dos dados consultados. Os limites revisados da APA de Guaraqueçaba e do PARNA de Superagui são apresentados na figura 8. 
XVII Simpósio Brasileiro de Geografia Fisica Aplicada

I Congresso Nacional de Geografia Física
OS DESAFIOS DA GEOGRAFIA FÍSICA NA FRONTEIRA DO CONHECIMENTO

Instituto de Geociências - Unicamp

Campinas - SP

28 de Junho à 02 de Julho de 2017

Quadro IV - Comparação da área dos limites disponíveis para a APA de Guaraqueçaba

\begin{tabular}{|c|c|c|}
\hline Limites da área de abrangência do estudo & Área em km² & Diferença em relação ao novo limite \\
\hline Novo limite gerado & $2.818,8501$ & - \\
\hline ICMBio & $2.827,0000$ & $+0,29 \%$ \\
\hline WWF & $2.824,4285$ & $+0,20 \%$ \\
\hline MMA & $2.807,2010$ & $-0,41 \%$ \\
\hline
\end{tabular}
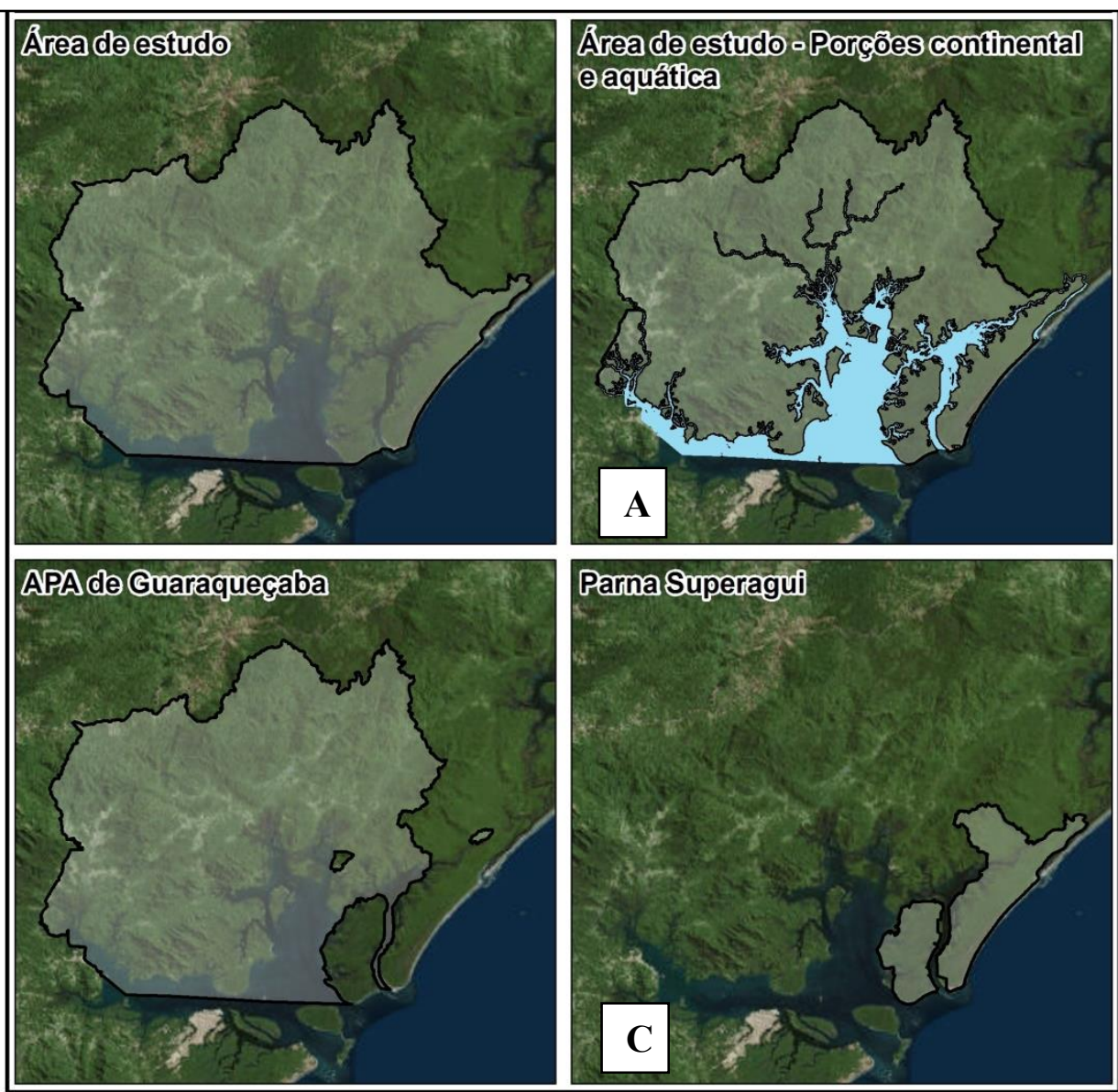

D

revisados para a área de estudo. $8 \mathrm{a}$ - Área de abrangência do estudo. $8 \mathrm{~b}$ - Porção continental e aquatica da área de estudo. 8c - APA de Guaraqueçaba. 8d - PARNA Superagui. Fonte: Os autores (2017).

Foi identificada uma pequena área próxima ao canal da Ararapira pertencente à APA de Guaraqueçaba, porém sem conexão terrestre, ou seja, uma "ilha de APA" (figura 8c). Essa pequena porção territorial é resultado da separação do PARNA de Superagui (figura 8d) da APA de Guaraqueçaba em 1989 (Decreto $\mathrm{n}^{\circ} 97.688$ - 1989).A área das UCs federaisestudadas é apresentada no quadro V, sendo a área da APA de Guaraqueçaba calculada sem considerar o PARNA de Superagui.Foi elaborado um novo memorial descritivo para a APA de Guaraqueçaba e PARNA de Superagui a partir das folhas topográficas 1:25.000, encaminhado ao ICMBio. 
XVII Simpósio Brasileiro de Geografia Fisica Aplicada

I Congresso Nacional

de Geografia Física
OS DESAFIOS DA GEOGRAFIA FÍSICA NA FRONTEIRA DO CONHECIMENTO

Instituto de Geociências - Unicamp

Campinas - SP

28 de Junho à 02 de Julho de 2017

QuadroV - Área das UCs presentes no interior da área de estudo

\begin{tabular}{|c|c|c|}
\hline Unidade de Conservação & Área em km $\mathbf{~ k m}^{\mathbf{2}}$ & Porcentagem em relação à área de estudo \\
\hline APA de Guaraqueçaba & $2.454,06$ & $73,34 \%$ \\
\hline PARNA de Superaqui & 341,14 & $12,10 \%$ \\
\hline Outras áreas* & 23,65 & $0,84 \%$ \\
\hline Total & $\mathbf{2 . 8 1 8 , 8 5}$ & $\mathbf{1 0 0 \%}$ \\
\hline
\end{tabular}

*Áréas de exclusão = comunidades pesqueiras + sede do municípiode Guaraqueçaba)

A verificação da topologia foi aplicada com êxito em todos os dados geoespaciais vetoriais do BDG. Os principais erros identificados foram vazios e sobreposições entre os polígonos e pontos duplicados (figura 9). Nos polígonos, esses erros prejudicam a mensuração de áreas, dificultando ou até impedindo análises espaciais. Indicativos comuns de erros topológicos sãoobservados quando a soma da área de todos os polígonos (solos, unidades geológicas, vegetação, entre outros) é superior à área total da área de estudo (DEVILLERS, R.; JEANSOULIN, 2006; PAZ; SAMPAIO, 2016).

\section{Exemplos de erros de topologia encontrados}
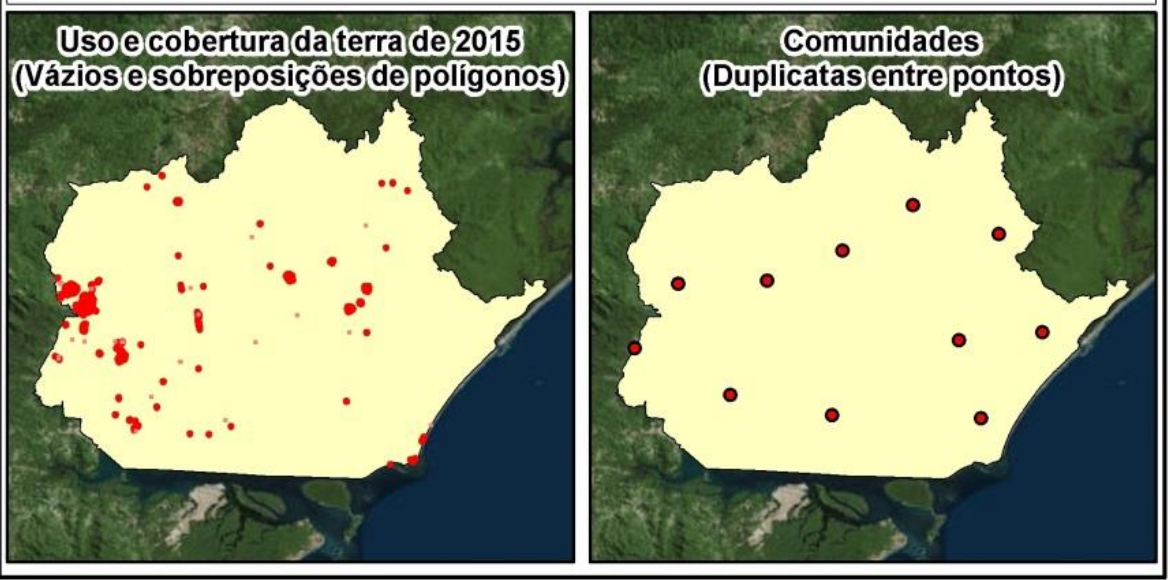

nomes dos dados geoespaciais. Fonte: Os autores (2017)

Figura 9 - Padronização dos

Os metadados ganham destaque por preservar informações importantes dos dados geoespaciais, podendo ser usados numa futura aplicação do dado ou mesmo na sua atualização. Outra importância dos metadados é a compatibilidade com o sistema geonetwork (adotado pelo governo federal), o qual permite a organização e consulta de uma base de dados (metadados) pela Internet.

Com o BDG operacional, sua função como subsídio à elaboração do diagnóstico ambiental é materializado na produção de mapas temáticos e cartogramas (figura 10). Foram produzidos 22 cartogramas inseridos no corpo do texto do diagnóstico e29 mapas temáticos nos anexos do documento. 

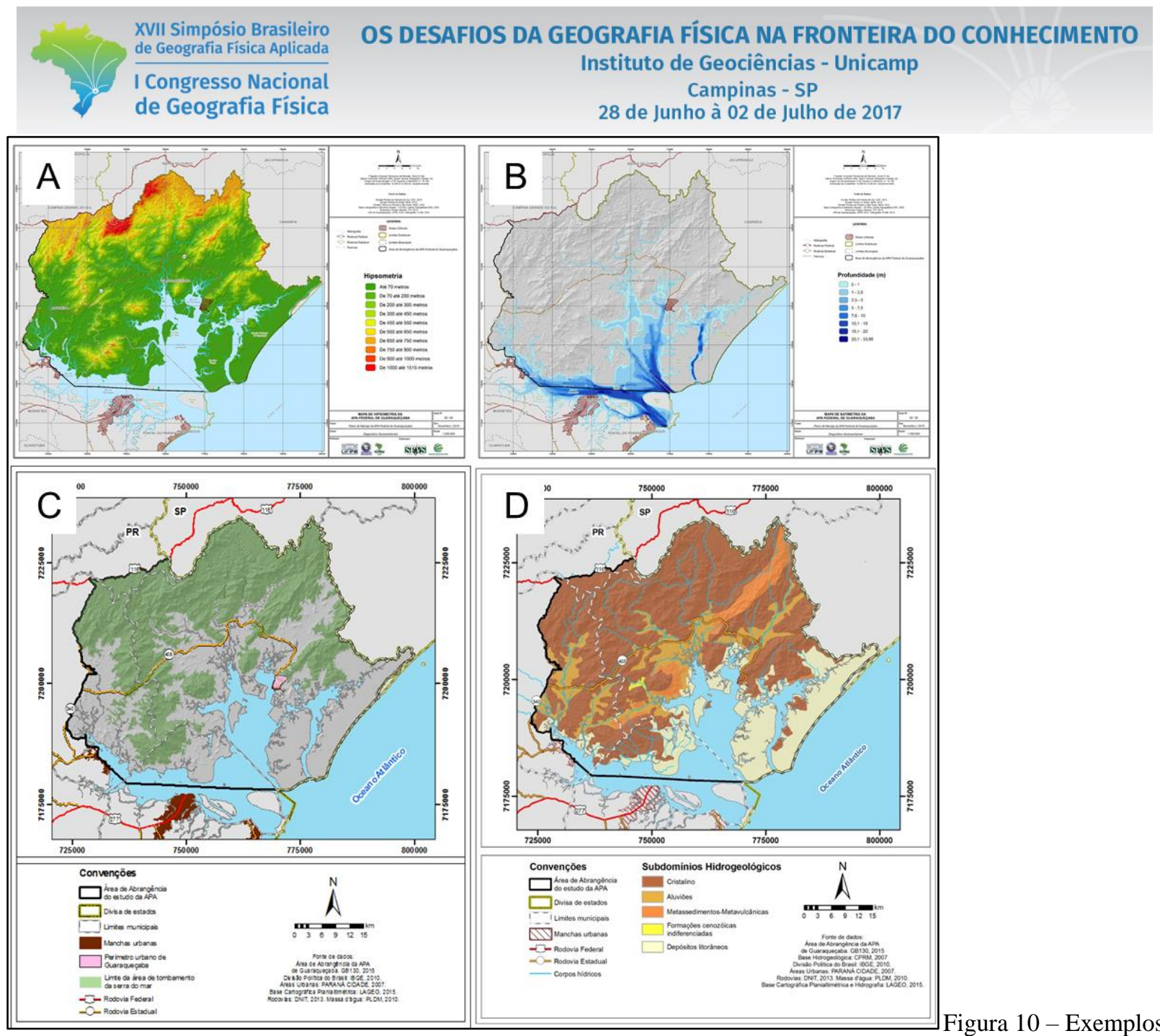

Figura 10 - Exemplos de produtos cartográficos gerados para o diagnóstico da APA de Guaraqueçaba. Fonte: Paula et al. (2015).

\section{Considerações finais}

A proposta para elaboração do BDG atende as demandas para elaboração do diagnóstico ambiental, uma vez que contribuí na organização e distribuição de dados geoespaciais com qualidade, possibilitando a elaboração de produtos cartográficos, sendo bem recebida pelos analistas ambientais do ICMBio.

A proposta apresenta critérios bem definidos, o que permite a reprodução da metodologia em outras UCs. Outro ponto importante é a interoperabilidade dos dados geoespaciais através do controle de qualidade, permitindo novas aplicações para os dados ou mesmo sua eventual atualização.

Por fim, cabe destacar a parceria entre a UFPR e o ICMBio, o que possibilita que as metodologias desenvolvidas dentro da universidade possam ser aplicadas na prática profissional, permitindo um constante aperfeiçoamento tanto de pesquisas aplicadas quanto da formação profissional dos discentes de graduação e pós-graduação em Geografia da UFPR. 


\section{Referências}

CAVELLANI, C. L. Sig, cartografia e limites territoriais - Análise do litígio entre Paraná E São Paulo. In: Congreso Iberoamericano de Estudios Territoriales y Ambientales, 6., 2014, São Paulo. Anais...São Paulo: USP, 2014. p. 3323 3339. Disponível em: <http://6cieta.org/arquivos-anais/eixo6/Caio\%20Lourencini\%20Cavellani.pdf> acesso em 28 fev. 2017.

CONCAR - COMISSÃO NACIONAL DE CARTOGRAFIA. Perfil de Metadados Geoespaciais do Brasil (Perfil MGB), Conteúdo de Metadados Geoespaciais em conformidade com a norma ISO 19115:2003, v. 1, p.164, 2009. Disponível em: <http://www.sieg.go.gov.br/downloads/Perfil_de_Metadados.pdf > acesso em: 28 fev. 2017.

COUTINHO, L. A. Banco de dados geográfico de desastres naturais. Projecto conceitual, inventariação e proposta para difusão dos dados. 2010. 99 f. Dissertação (Mestrado em gestão do território, área de especialização em Detecção Remota e Sistemas de Informações Geográficas) - Universidade Nova de Lisboa. Lisboa. 2010. Disponível em: <https://run.unl.pt/bitstream/10362/4240/1/DISSERTA\%C3\%87\%C3\%83O.pdf> acesso em: 28 fev. 2017.

DALAZOANA, R.; FREITAS, S. R. C. Efeitos na cartografia devido a evolução do sistemaGeodésico brasileiro e adoção de um referencialgeocêntrico. Revista Brasileira de Cartografia. v. 1, n. 54. p. 66-76, 2002. Disponível em: <http://www.lsie.unb.br/rbc/index.php/rbc/article/view/190> acesso em 28 fev. 2017.

DEVILLERS, R.; JEANSOULIN, R. Fundamentals of spatial data quality.ISTE Publishing Company, 2006. Disponível

<http://dlia.ir/Scientific/e_book/Geography_Anthropology_Recreation/Geography_(General)/001646.pdf> Acesso em: 28 fev. 2017.

DSG - DIRETORIA DO SERVIÇO GEÓGRAFICO. Especificação técnica para aquisição de dados geoespaciais vetoriais (ET-ADGV).Ministério da Defesa, Exército Brasileiro, Departamento de Ciência e Tecnologia. Brasília-

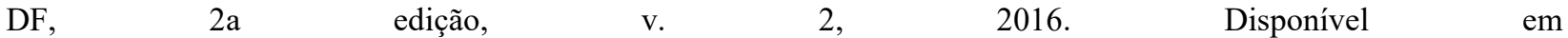
<http://www.geoportal.eb.mil.br/images/PDF/ADGV_Defesa_FT_2016_2a_Edicao_2016.zip> acesso em: 28 fev. 2017.

ESRI. Spatial Analyst Tutorial. Esri, 2010.

IBGE - Instituto Brasileiro de Geografia e Estatística. Define a data de término do período de transição definido na RPR 01/2005 e dá outrasprovidências sobre a transformação entre os referenciais geodésicos adotados no Brasil.Resolução da presidência. $1^{\text {a }}$ edição, v. 1, 2015. Disponível em: <ftp://geoftp.ibge.gov.br/metodos_e_outros_documentos_de_referencia/normas/rpr_01_2015_sirgas2000.pdf> acesso em: 28 fev. 2017.

ISO - International Organization for Standardization. ISO 19114 - Geographic information - Quality evaluation procedures. Switzerland. 2003a. Disponível em: <https://www.iso.org/standard/26019.html > acesso em: 28 fev. 2017.

ISO - International Organization for Standardization. ISO 19115 - Geographic Information - Metadata. Switzerland. 2003b. Disponível em: <https://www.iso.org/standard/26020.html> acesso em: 28 fev. 2017. 
ISO - International Organization for Standardization. ISO 19157 - Geographic Information - Data Quality. Switzerland. 2013. Disponível em: <https://www.iso.org/standard/32575.html > acesso em: 28 fev. 2017.

PAUlA, E. V. et al. Diagnóstico de subsídio ao Plano de Manejo da APA de Guaraqueçaba. v. 2, p. $280,2015$.

PAZ, O. L. S.; SAMPAIO, T. V. M. Qualidade de Dados Espaciais Vetoriais Disponibilizados para o Estado do Paraná. Anais da XXXII Semana de Geografia da Universidade Estadual de Londrina e do I Encontro de Tecnologias Geográficas e Contemporaneidades. Anais...Londrina: $2016 . \quad$ Disponível em: <http://www.uel.br/cce/geo/arquivos/anais_semana_geografia_2016.pdf> acesso em 28 fev. 2017.

TIMBÓ, M. A. Elementos de cartografia. Universidade Federal de Minas Gerais. Belo Horizonte, Brasil, 57p, 2001. Disponível em: <http://www.csr.ufmg.br/carto1/elementoscartografia_timbo.pdf> acesso em 28 fev. 2017. 